\title{
An Empirical Study on the Relationship between Metacognitive Strategies and Online-learning Behavior \& Test Achievements
}

\author{
Yuhui Liu \\ Beijing University of Technology, Beijing, China \\ Email: liuyuhui@bjut.edu.cn \\ Hao Feng \\ Beijing University of Technology, Beijing, China \\ Email: fenghao@emails.bjut.edu.cn
}

\begin{abstract}
By using Wen Qiufang's Questionnaire on English Learning Strategies, 93 students from thirteen different majors in Beijing University of Technology are surveyed about their use of metacognitive strategies and self-learning on line. Based on the survey, the relationship between metacognitive strategies and online-learning behavior \& test achievements is analyzed with suggestions for strategy training and ability development.
\end{abstract}

Index Terms - metacognitive strategies, online learning behavior, test achievements, self-learning ability

\section{RESEARCH BACKGROUND}

College English Corriculum Requirements (Requirements for short) was issued by Higher Education Department of Education Ministry in 2004, which specifies "the objective of college English is to develop students' ability in a well-rounded way, especially in listening and speaking, so that in their future studies and careers as well as social interactions they will be able to communicate effectively, and at the same time enhance their ability to study independently and improve their general cultural awareness so as to meet the needs of China's social development and international changes." To achieve the teaching objective, college English teaching reform has begun in Beijing University of Technology (BJUT for short) since September, 2004 through reforming course design by analyzing students' needs and social needs, and reforming teaching modes by adopting "Computer- and Classroom-Based College English Teaching Model" recommended by Requirements. In addition, a matching language learning center has been founded; local area network has been established which can provide students with opportunities of self-learning by using computers, or to do net discussion, testing and so on. The new teaching model, especially self-learning on line, aroused the students' interest in learning English and provided them with better learning environment in developing their ability, especially the ability of listening and speaking by listening to, viewing and imitating the native speakers on line. The reform measures have been applied and tried out on the college English teaching of four grades from 2004 to 2007, with good teaching results achieved by cultivating a group of students with strong ability and excellent achievements. A case in point is that there are more and more students in the university enjoying practice activities such as speaking and debating, resulting in the first prize of "FLTRP cup" national English debate contest in 2007, the second prize of "CCTV cup" national English speaking competition in 2006 and many other national and international prizes and awards.

However, it has been discovered during the teaching process that there are some students who hardly benefit from the new teaching model. Their achievements and ability have little improvement. Therefore, the authors propose that external conditions such as computers and network are not enough to improve the achievements and ability of the majority of the students. What is more important is to develop and improve students' self-learning ability. Therefore, the investigation and training of learning strategies, especially metacognitive strategies have been conducted.

\section{LITERATURE REVIEW}

\section{A. Researches on Learning Strategies Abroad}

Researches on second language and foreign language learning strategies have begun since mid 1970s. Rubin from America and Nunan from Canada were pioneers in this field. Later, researches on learner-centered foreign language learning strategies gradually became heated. Early researches mainly focused on successful foreign language learners. Strategies such as to grasp practice opportunity, to control one's emotion or to learn a foreign language systematically and so on are regarded by researchers as common features of all successful learners. Research data from Chamot \& 
Kuper (1989) showed that all learners use strategies, while the difference is whether they can use them flexibly and properly, which lies in learners' ability of self-evaluation and regulation of study. Self-evaluation and regulation ability is an important part of metacognition. Skehan (1989) believes that reflection, supervising and evaluation are key factors to use learning strategies. Otherwise, learners may just obtain some scattered skills which have no good to the whole learning. Succeeding related researches approve that metacognition is underlying reasons to reveal difference in test achievements.

\section{B. Researches on Learning Strategies at Home}

Domestic researches on foreign language learning strategies have begun since the beginning of 1980s, while overall start was after 1993, which has been undertaken by scholars such as Wen has reached many achievements. So far, there are six national scientific research projects in English learning strategy field with six monographs (Cheng \& Zheng, 2002, Wen, 1996, 2003, Wu, 2002, Xiao, 1997, Yin, 2002) and two thesis collections (Wen \& Wang 2003a, 2003b) published. Many scholars have begun to do further researches about metacognitive strategies. Ma et al. (2003) classified strategies into six groups of sub-strategies when studying influences of strategy application on language level, that is, memory, cognition, compensation, metacognition, emotion, and society. Their researches indicate that the language level changes from high to low according to the variation of application frequency of metacognitive strategies from high to low. The research of Yu et al. (2003) has found that among college students as well as high school students, good English readers generally have better mectacognitive strategy awareness, which supports previous researches. Wei \& Zou (2003) found through investigation that students who are good at English reading can adopt proper learning strategies effectively, especially metacognitive strategies during reading process. Based on the research On Method Difference of Successful and Unsuccessful English Learners by Wen (1995), Mei (2003) proposes that the difference between good and poor students is, in fact, the difference of metacognitive level. Wu \& Wang (1998), Yang \& Zhang (2002) approve that metacognitive strategies have a positive influence on vocabulary learning, reading comprehension and writing.

\section{Wen Qiufang's Research on English Metacognitive Strategies}

Wen's research on English metacognitive strategies shows that there is a great difference between successful and unsuccessful English learners in the use of metacognitive strategies (Wen, 2003). The former have stronger awareness to use metacognitive strategies and show initiative in English learning, while the latter have comparatively weaker awareness in using metacognitive strategies and are aimless and passive in English learning. Wen (2003) classifies strategies into management strategies and language learning strategies. The management strategies are connected with learning process, including plan making, strategy selecting, self-monitoring, self-evaluation and self-adjustment, which are metacognitive strategies; the management strategies include not only cognitive management process, but also emotional management process. The language learning strategies are closely connected with language learning material, and merely used in language learning. Wen (2003) agrees with O'Malley \& Chamot (1990) that whether a learner can achieve success or not in learning depends greatly on the use of metacognitive strategies.

The above researches prove that metacognitive strategies function and have great influence on English learning in the aspects such as vocabulary learning, reading comprehension, writing and so on. But the research on how metacognitive strategies function in teaching and learning English by adopting "Computer- and Classroom-Based College English Teaching Model", especially when online self-learning becomes an necessity, is mostly limited to the investigation based on questionnaires and tests (Xiao \& Cao, 2005, He \& Wang, 2007). Besides the questionnaire and the test, the research of this paper is based on more specific statistics of online self-learning behavior of self-learning and self testing to further reveal the relationship between metacognitive strategies, online self-learning behavior and test achievements of students.

\section{RESEARCH DESIGN}

\section{A. Subjects}

The population of the research is 1724 students from grade 2008 in BJUT. The sample of 93 students from 13 colleges of the university, including colleges of engineering, science and humanities respectively, are randomly chosen. All the students are in their first year of college English study.

\section{B. Questions}

(1) Is there any difference in the use of metacognitive strategies between the low mark group and the high mark group of test achievements of the subjects?

(2) Is there any difference in the time and frequency of online self-learning and testing between groups different in using metacognitive strategies?

(3) Is there any relationship between the time of online self-learning, the frequency of online self-testing and the final test achievements?

\section{Instruments}


A questionnaire of 9 items about cognitive management strategies (metacognitive strategies) selected from the fourth part (item1-7, 9, 12) of Wen 's Questionnaire on English Learning Strategies is adopted in this research (Wen, 2006). In this part, Likert Scale is used, in which five scales are chosen to indicate the informants' degree of agreement to the items with 1 indicating completely disagree and 5 indicating completely agree. The nine metacognitive strategies included in this study constitute three sets, which include three strategies for self-planning, self-evaluation and self-monitoring respectively.

The subjects' online self-learning record is adopted. The students were encouraged rather than demanded to learn autonomously on line. The time they spent (hours) was recorded for one semester.

The subjects' online self-testing record is adopted. The students were encouraged rather than demanded to do online self-testing, which consisted of 16 sets of test questions, including 8 sets of listening questions and 8 sets of reading and writing questions respectively. The sets of the tests they had finished (times) were recorded for one semester.

The test achievements of the subjects are adopted. The students took the final examination, the test paper was chosen randomly from the test bank used for regular final examinations for all the students in the university, and the scores were collected and analyzed.

\section{Data Analysis}

There are 4 variables (X) in this study. Test achievements (scores) X1 is taken from the final examination of the first semester, sorting X1 by low mark group, mid mark group and high mark group. Online self-learning record (hours) X2 is taken from the first semester online record; the most is 45 hours and the least is 4 . Online self-testing record (times) $\mathrm{X} 3$ is taken from the first semester online record; the most is 16 times, and the least is 0 . Level of using cognitive strategies (scores) X4 is taken from mean score of each cognitive strategy item, sorting X4 by low mark group, mid mark group and high mark group.

The data collected were put into LSAS (Learning Strategies Analysis System) developed by Wen \& Wang (2006) in the website of http://www.jyw.cn, which has all the functions of SPSS. Mean score and standard deviation were employed to describe the application level and tendency of variables. Independent sample mean score difference " $t$ " test was done to test the difference between variables. Pearson correlation coefficient was done to find the correlation degree between online self-learning, online self-testing and test achievements.

\section{RESEARCH RESULTS AND DISCUSSION}

\section{A. Difference in Using Metacognitive Strategies}

Table 1 presents a summary of the analysis of data obtained from the results of the final examination and the results of the strategy analysis.

TABLE 1

T-TEST RESULTS OF USING METACOGNITIVE STRATEGIES

\begin{tabular}{|l|l|l|l|l|l|l|}
\hline \multirow{2}{*}{ Classification } & \multicolumn{2}{l}{$\begin{array}{l}\text { Low mark group } \\
(25 \text { students })\end{array}$} & \multicolumn{2}{l}{$\begin{array}{l}\text { High mark group } \\
(25 \text { students })\end{array}$} & \multirow{2}{*}{ “T” value } & Significance level \\
\cline { 2 - 7 } & $\mathrm{X}$ & $\mathrm{S}$ & $\mathrm{X}$ & $\mathrm{S}$ & & \\
\hline $\begin{array}{l}\text { Metacognitive learning } \\
\text { strategies }\end{array}$ & 3.11 & 0.694 & 3.548 & 0.796 & 2.152 & 0.05 \\
\hline
\end{tabular}

Based on the results of the final examination, 25 subjects constitute the low mark group and another 25 the high mark group. Mean scores (X) and standard divisions (S) in using metacognitive learning strategies between the two groups are compared. The results show that there is a significant difference between high and low mark groups in metacognitive strategies. The high mark group uses more metacognitive strategies in average. The result agrees with that of the research done by Han \&Liu (2007).

\section{B. Difference in Online Self-learning, Online Self-testing and Test Achievements}

Table 2 presents a summary of the analysis of data obtained from the results of the strategy analysis, online self-learning, online self-testing and final test achievements.

TABLE 2

T-TEST RESULTS OF ONLINE SELF-LEARNING, ONLINE SELF-TESTING AND TEST ACHIEVEMENTS

\begin{tabular}{|l|l|l|l|l|l|l|}
\hline \multirow{2}{*}{ Classification } & \multicolumn{2}{l}{$\begin{array}{l}\text { Low mark group (31 } \\
\text { students) }\end{array}$} & \multicolumn{2}{l}{$\begin{array}{l}\text { High mark group } \\
\text { (30 students) }\end{array}$} & \multirow{2}{*}{ “T” value } & Significance level \\
\cline { 2 - 8 } & $\mathrm{X}$ & $\mathrm{S}$ & $\mathrm{X}$ & $\mathrm{S}$ & & \\
\hline Online self-learning (hours) & 16.774 & 7.766 & 21.467 & 9.316 & 2.134 & 0.05 \\
\hline Online self-testing (times) & 7.429 & 4.912 & 11.767 & 4.89 & 3.456 & 0.01 \\
\hline Test achievements (scores) & 74.387 & 7.855 & 79.367 & 9.551 & 2.220 & 0.05 \\
\hline
\end{tabular}

Based on the results of the strategy analysis, 31 subjects constitute the low mark group and another 30 the high mark 
group. Mean scores (X) and standard divisions (S) in online self-learning (hours), online self-testing (times) and final test achievements (scores) between the two groups are compared. The results show that there is significant difference between high and low mark groups in online self-learning. Online self-learning time can be considered one of the aspects which suggest one's self-learning ability. While other means of self-learning, such as disc, text books and other learning materials can also help to promote one's test achievements, it is true that the students in high mark group of metatcognitive strategies spend more time in average in online self-learning than those in low mark group.

Compared with online self-learning, online self-testing is much more persuasive because the tests must be done and handed in online. Therefore, there is extremely significant difference between high and low mark groups of cognitive strategies in online self-testing record (times). The high mark group students have done many more times of online self-testing in average. The online self-testing content and scores are not included in the statistics, for, besides metacognitive strategies, they involve other cognitive learning strategies, which are not within the discussion of this paper.

According to the above two statistic results, it is obvious that there is significant difference between high and low mark groups of metacognitive strategies in test achievements, and the high mark group has better average final test achievements, which has also been approved by Table 1 .

\section{Correlation between Online Self-learning, Online Self-testing and Final Test Achievements}

Table 3 \& Table 4 present a summary of the correlation analysis of data obtained from the results of online self-learning, online self-testing and final test achievements.

TABLE 3

CORRELATION ANALYSIS RESULTS OF ONLINE SELF-LEARNING AND FINAL TEST ACHIEVEMENTS

\begin{tabular}{|l|l|l|}
\hline Classification & Test achievements & Online self-learning (hours) \\
\hline Test achievements & 1.00 & 0.599 \\
\hline Online self-learning (hours) & 0.599 & 1.00 \\
\hline
\end{tabular}

TABLE 4

CORRELATION ANALYSIS RESULTS OF ONLINE SELF-TESTING AND FINAL TEST ACHIEVEMENTS

\begin{tabular}{|l|l|l|}
\hline Classification & Test achievements & Online self-testing (times) \\
\hline Test achievements & 1.00 & 0.498 \\
\hline Online self-testing (times) & 0.498 & 1.00 \\
\hline
\end{tabular}

The results show that online self-learning and final test achievements are positively correlated (0.599), with extremely significant difference in total zero correlation; that is, the more online self-learning students have, the better their test achievements are. Online self-testing and test achievements are positively correlated (0.498), with extremely significant difference in total zero correlation; that is, the more online tests students do, the better their test achievements are.

The results of the above three analysis suggest that students who are better aware of the use of metacognitive strategies show initiative in learning, having better self-learning ability and test achievements. It agrees with Wen's research result. Therefore, we can train metacognitive strategies accordingly by analyzing students' efforts first, hoping to improve test achievements of poor learners and develop their ability.

\section{CONCLUSION}

\section{A. Major Findings}

The results of the research have answered the research questions with the findings.

(1)There is a significant difference between the low mark group and the high mark group of the subjects in the use of metacognitive strategies. The students in the high mark group of test achievements use more metacognitive strategies.

(2)There is an extremely significant difference in the time and frequency of online self-learning and testing between groups different in using metacognitive strategies. The students in the high mark group of cognitive strategies spend more time in average in online self-learning and do more online tests than those in the low mark group.

(3)There is a positive correlation between the time of online self-learning, the frequency of online self-testing and the final test achievements. The students who spend more time in online self-learning and do more online tests achieve higher scores in average in the final examination.

In conclusion, metacognitive learning strategies function in students' online learning behavior and test achievements.

\section{B. Suggestions for Further Research}

The results of the research prove statistically that metacognitive strategies function in students' online learning behavior and test achievements. Therefore, it is desirable that the further researches focus on strategy training. Strategy training has been done and studied quite a lot even in recent years, but mostly for listening, reading and writing (Shen \& 
Song, 2008). Strategy training for online self-learning is a new area for study and practice. Learning strategies, especially metacognitive strategies are important for online self-learning, for facing the vast amount of learning resources, learners need the ability to plan, monitor and evaluate in order to acquire learning efficiency and develop self-learning ability.

In summary, learning strategies, especially metacognitive strategies, are basis to train and improve self-learning ability, and in turn self-learning ability can help students improve test achievements and train language using ability. Therefore, it is imperative to strengthen the training of students' learning strategies, especially metacognitive strategies.

\section{REFERENCES}

[1] Chamot. A. U. \& L. Kupper. (1989). Learning strategies in foreign language instruction. Foreign Language Annals 22, 13-24.

[2] Cheng, Xiaotang \& Zheng, Min. (2002). English learning strategies. Beijing: Foreign Language Teaching and Research Press.

[3] Han, Shuguang \& Liu, Yuhui. (2008). The correlation between metacognition and English achievement of college English students in the context of on-line self-learning. China Electric Power Education 4, 178-180.

[4] He, Mingjia \&Wang Guan. (2007). Autonomous learning strategies and efficiency \&aptitude of English learners. Teaching English in China 30, 111-117.

[5] Ma, Xiaomei et al. (2003). On learning style of college English learners. In Liu, Runqing \& Dai, Manchun (eds.), Researches on College English Teaching Reform and Development Strategies in China. Beijing: Foreign Language Teaching and Research Press, 183-197.

[6] Mei, Jianeng. (2003). Metacognition and after-class learning of college students. Guangxi Social Sciences 5, 186-187.

[7] Nunan, D. (1997). Strategy training in the language classroom: An empirical investigation. RELC Journal 26, 56-81.

[8] O’Malley, J. M., \& A. U. Chamot. (1990). Learning strategies in second language acquisition. Cambridge, England: Cambridge University Press.

[9] Rubin, J. (1975). What the "good language learner" can teach us. TESOL Quarterly 9, 41- 45.

[10] Rubin, J. (1981). Study of cognitive process in second language learning. Applied Linguistics 11, 117-31.

[11] Shen, Yanxia \& Song, Julei. (2008). A review of English learning strategy in China. English Language Teaching 1, 116-120.

[12] Skehan, P. (1989). Individual Differences in Second Language Learning. London: Edward Arnold.

[13] Wei, Ruyao \& Zou, Aimin. (2003). Cognitive Strategies and Reading Comprehension. Shan Dong Foreign Languages Journal 3,47-49.

[14] Wen, Qiufang. (1995). Differences between successful English learners and unsuccessful English learners in learning methods. Foreign Language Teaching and Research 3, 61-66.

[15] Wen, Qiufang. (1996). On English Learning Strategies. Shanghai: Shanghai Foreign Language Education Press.

[16] Wen, Qiufang. (2003). A Successful Road to English Learning. Shanghai: Shanghai Foreign Language Education Press.

[17] Wen, Qiufang \& Wang, Lifei. (2003a). Empirical Researches on English Learning Strategies. Xi'an: Shaanxi Normal University Press.

[18] Wen, Qiufang \& Wang, Lifei. (2003b). Theoretical Researches on English Learning Strategies. Xi'an: Shaanxi Normal University Press.

[19] Wen, Qiufang \& Wang, Jiong. (2006). Learning Strategies Analysis System. http://www.jyw.cn/Index.html

[20] Wu, Benhu. (2002). English Learning Strategies. Hefei: Anhui Education Press.

[21] Wu, Xia \& Wang Qiang. (1998). Vocabulary learning strategies of non-English college students. Foreign Language Teaching and Research 1, 53-57.

[22] Xiao, Jianzhuang. (1997). English Learning Strategies. Beijing: Modern Publish Press.

[23] Xiao, Wuyun \& Cao, Qunying. (2005). Teaching research on metacognitive strategies and learner autonomy. Journal of Educational Science of Hunan Normal University 5, 108-111.

[24] Yang, Xiaohu \& Zhang, Wenpeng. (2002). The correlation between metacognition and EFL reading comprehension of Chinese college students. Foreign Language Teaching and Research 3, 213-218.

[25] Yin, Fulin. (2002). On English Learning. Heifei: China Science and Technology University Press.

[26] Yu, Ping et al. (2003). On metacognition and English reading. Journal of Yunan Normal University 5, 40-44.

Yuhui Liu is a professor in College of Foreign Languages, Beijing University of Technology, Beijing, China and has published more than 30 academic papers on English teaching \& learning and on conversation analysis, and more than 20 textbooks and workbooks on vocabulary, listening, reading and writing as the first author or chief editor; she has been in charge of more than 10 academic research projects about teaching methodology, teaching reform, and conversational analysis \& teaching of listening and speaking.

Hao Feng is currently a graduate student in College of Foreign Languages, Beijing University of Technology, Beijing, China. Her main interests include conversation analysis and language teaching. 